\title{
Sequential organ failure assessment score as prognostic marker in critically ill patients in a tertiary care intensive care unit
}

Introduction: Sepsis is one of the most important causes of mortality in the intensive care setting. An effective predictor of prognosis of sepsis is required to assess morbidity and mortality of this condition. In this study, sepsis in the intensive care unit (ICU) of a tertiary care hospital was evaluated, with specific reference to clinical features and causative organisms. The sequential organ failure assessment (SOFA) score was calculated to assess the severity of sepsis and multi-organ failure at presentation and after $48 \mathrm{~h}$. The correlation of SOFA and mean SOFA scores with outcome was studied. Materials and Methods: This was a prospective, observational, cohort study carried out in a tertiary care teaching hospital. Forty consecutive cases of septicemia were studied. Detailed history, clinical features, and SOFA score was recorded to assess the disease severity at the time of presentation and after $48 \mathrm{~h}$. Inclusion of patients in the study was performed using the American College of Chest Physicians/Society of Critical Care Medicine (ACCP/SCCM) definition of sepsis. Two sample $t$-test and $95 \%$ confidence interval (CI) for difference of mean was applied. Results: When the SOFA score was $<7$, the mortality was $56 \%$. It increased to $70 \%$ when the score was 8-15 ( $P=0.0989, t$ value: 1.69 , Mean difference: 2.12 , $95 \% \mathrm{Cl}: 0.41-4.665)$. Patients with SOFA score $<7$ after $48 \mathrm{~h}$ had $52 \%$ mortality and it increased to $88 \%$ when the score was $8-15$. The mean SOFA score at 48 h was 6.96 in patients who died and 2.5 in those who improved $(P<0.001$, $t$ value: 4.332 , mean difference: $4.39,95 \% \mathrm{Cl}: 2.34-6.44)$. Hence, the predictive value for mortality of SOFA score was better at $48 \mathrm{~h}$ than at presentation. Conclusions: Sequential assessment of organ dysfunction in ICU at presentation and at $48 \mathrm{~h}$ is a good indicator of prognosis. Both mean and highest SOFA scores are particularly useful predictors of outcome, independent of the initial score. A high SOFA score at $48 \mathrm{~h}$ of presentation predicts an increased mortality rate.

Key words: Mortality, multi-organ dysfunction, sepsis, sequential organ failure assessment score

Address for the Correspondence:

Dr. Zubin D. Sharma, Department of Medicine,

Pad. Dr. D.Y. Patil Medical College and Research Hospital, Sant Tukaram Nagar, Pimpri, Pune - 411018 ,

Maharashtra, India. E-mail: drzubinsharma@gmail.

com

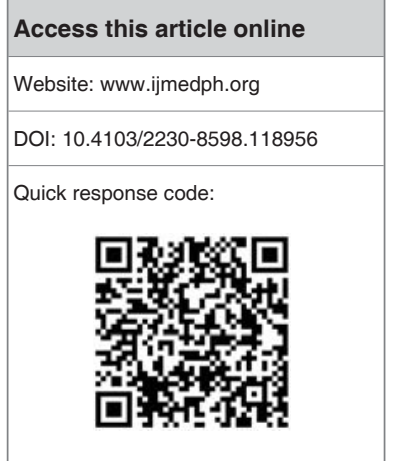

\section{INTRODUCTION}

Sepsis is one of the important problems in medicine due to its complexity from pathophysiologic, clinical, and therapeutic viewpoints. Although several definitions have been proposed for this syndrome, in general, it can be assumed that it represents the clinical manifestation of a systemic response of the body to infection or to an inflammatory-associated acute disease. ${ }^{[1,2]}$

Mortality rates as a result of sepsis are associated with a pattern characterized by progressive dysfunction or failure of non-pulmonary organ systems, including neurologic, coagulation, and renal functions over the first 3 days. ${ }^{[3]}$

Various scoring systems such as Glasgow scale, APACHE II and III and sequential organ failure assessment (SOFA) scoring have been validated and are being used in predicting prognosis of patients admitted in intensive care unit (ICU). In this study, sepsis in the ICU of a tertiary care hospital was evaluated, with specific reference to clinical features and causative organisms. The SOFA score was calculated to assess the severity of sepsis and multi-organ failure at presentation and after $48 \mathrm{~h}$. These SOFA and mean SOFA scores were correlated with outcomes. Furthermore, multi-organ dysfunction was assessed with respect to organ systems involved and their correlation with mortality. Sequential 
assessment of organ dysfunction in patients in ICU at presentation and at $48 \mathrm{~h}$, is one of the important parameters for predicting mortality. ${ }^{[4]}$

\section{MATERIALS AND METHODS}

This was a prospective study, approved by the Ethical Review Board of a tertiary care teaching hospital in western India, which waived informed consent on the basis that this was a non-interventional epidemiological study. Forty cases of septicemia (over 18 years of age) admitted for more than $24 \mathrm{~h}$ to the 12 bedded medical ICU were studied. A detailed history was taken and the clinical features and causative organisms were studied. In patients with organ dysfunction or going into organ dysfunction, the incidence and outcome of sepsis and organ dysfunction was evaluated. Demographic, laboratory and clinical data were collected and the SOFA score (0-24) was calculated, on admission and at $48 \mathrm{~h}$ of presentation [Table 1]. In the calculation of the score, the worst values for each parameter in the $24 \mathrm{~h}$ period were used. The delta SOFA ( $\triangle \mathrm{SOFA}$ ) was calculated as the difference between the SOFA score at $48 \mathrm{~h}$ and the score on the day of admission to the ICU. ${ }^{[5]}$

Statistical software Epi Info version 3.4.3 developed by Centre of Disease Control and Prevention (CDC), Atlanta, USA was used; two sample $t$-test and $95 \%$ confidence interval for difference of mean were applied. Inclusion criteria were as per the ACCP/SCCM definition of sepsis. Sepsis was considered present if infection was highly suspected or proven and two or more of the systemic inflammatory response syndrome criteria were met. ${ }^{[6,7]}$

\section{RESULTS}

Out of 27 patients with sepsis having SOFA score $<7$ at presentation, there were $12(44 \%)$ survivors and 15 (56\%) non-survivors [Figure 1]. Out of 13 patients with SOFA score 8-15, there were $4(30 \%)$ survivors and $9(70 \%)$ non-survivors. Mean SOFA score of the patients who did not survive was 6.625 ; mean \pm SD was $6.625 \pm 3.8653$. The mean SOFA score of the patients who survived was 4.5 , mean $\pm \mathrm{SD}$ was $4.5 \pm 3.9328$ [Tables 2 and 3, Figure 2].

The SOFA score after $48 \mathrm{~h}$ was $<7$ in 31 patients. Out of these, there were $15(48 \%)$ survivors and $16(52 \%)$ non-survivors. Out of 9 patients with score between 8 and 15, there was $1(11.2 \%)$ survivor and $8(88 \%)$ non-survivors. Mean score of the patients who were non-survivors was 6.96; mean $\pm \mathrm{SD}$ was $6.9583 \pm 3.8653$. The score in those who survived was 2.5 , mean \pm SD was $2.5 \pm 2.5025(P<0.001)$ [Tables 4 and 5, Figure 2].

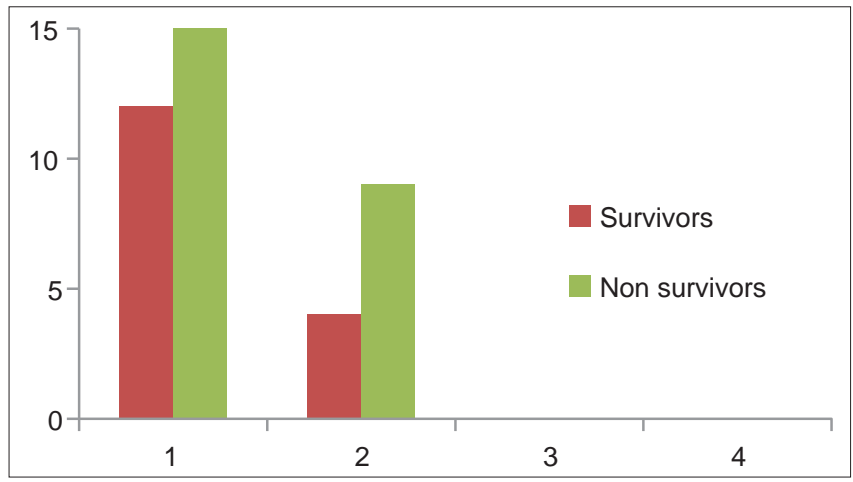

Figure 1: Number of patients according to sequential organ failure assessment score at presentation

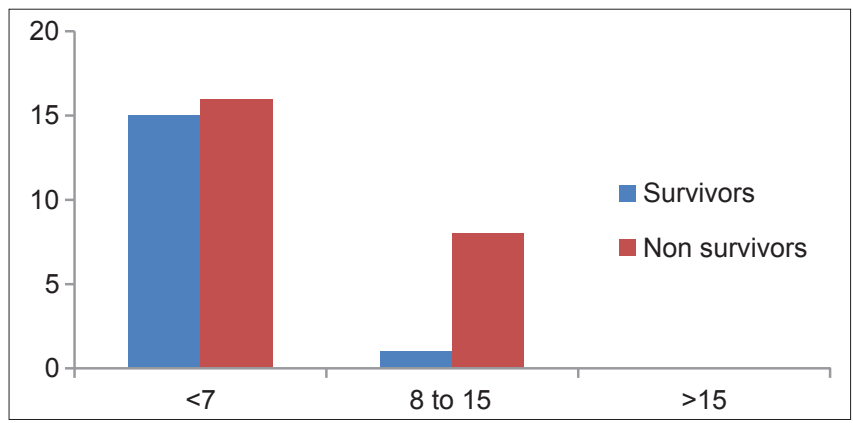

Figure 2: Number of patients according to sequential organ failure assessment score at $48 \mathrm{~h}$

$\begin{aligned} & \text { Table 2: Number of patients according to SOFA } \\
& \text { score at presentation }\end{aligned}$
\begin{tabular}{lcc}
\hline SOFA score & Survivors & Non-survivors \\
\hline$<7$ & 12 & 15 \\
$8-15$ & 4 & 9 \\
$>15$ & - & - \\
\hline
\end{tabular}

SOFA=Sequential organ failure assessment

\begin{tabular}{|c|c|c|c|c|c|}
\hline \multirow[t]{2}{*}{ Organ system } & \multicolumn{5}{|c|}{ Score } \\
\hline & 0 & 1 & 2 & 3 & 4 \\
\hline Respiratory: $\mathrm{PaO}_{2} / \mathrm{FiO}_{2}$ & $>400$ & $\leq 400$ & $\leq 300$ & $\leq 200$ & $\leq 100$ \\
\hline Renal: Creatinine (mg/dl) & $<1.2$ & $1.2-1.9$ & $2.0-3.4$ & 3.5-4.9; urine output $\leq 500 \mathrm{ml} /$ day & $>5.0$; urine output $<200 \mathrm{ml} /$ day \\
\hline Hepatic: Bilirubin (mg/dl) & $<1.2$ & $1.2-1.9$ & $2.0-5.9$ & $6.0-11.9$ & $>12.0$ \\
\hline $\begin{array}{l}\text { Cardiovascular: } \\
\text { Hypotension }\end{array}$ & $\begin{array}{c}\text { No } \\
\text { hypotension }\end{array}$ & MAP $<70 \mathrm{mmHg}$ & $\begin{array}{c}\text { Dopamine } \leq 5^{a} \\
\text { dobutamine } \\
\text { (any dose) }\end{array}$ & $\begin{array}{l}\text { Dopamine }>5^{\mathrm{a}} \text { or } \\
\text { epinephrine } \leq 0.1^{\mathrm{a}} \text { or } \\
\text { norepinephrine } \leq 0.1^{\mathrm{a}}\end{array}$ & $\begin{array}{l}\text { Dopamine }>15^{\mathrm{a}} \text { or } \\
\text { epinephrine }>0.1^{\mathrm{a}} \text { or } \\
\text { norepinephrine }>0.1^{\mathrm{a}}\end{array}$ \\
\hline $\begin{array}{l}\text { Hematologic: Platelet } \\
\text { count }\left(10^{3} / \mathrm{mcL}\right)\end{array}$ & $>150$ & $\leq 150$ & $\leq 100$ & $\leq 50$ & $\leq 20$ \\
\hline $\begin{array}{l}\text { Neurologic: Glasgow } \\
\text { coma scale score }\end{array}$ & 15 & $13-14$ & $10-12$ & $6-9$ & $<6$ \\
\hline
\end{tabular}

${ }^{2}$ Adrenergic agents administered for at least $1 \mathrm{~h}$ (doses given are in $\mu \mathrm{g} / \mathrm{kg} / \mathrm{min}$ ). $\mathrm{FiO}_{2}=$ Fractional inspired oxygen, MAP=Mean arterial pressure, $\mathrm{PaO}=\mathrm{Arterial}$ oxygen tension, SOFA=Sequential organ failure assessment 


\begin{tabular}{lcccccc}
\multicolumn{6}{l}{ Table 3: Correlation of outcomes with SOFA score } & \\
\hline Outcome & Observation & Mean & Standard deviation & Mean difference & Median & $95 \%$ Cl \\
\hline Survivors & 24 & 4.5000 & 3.9328 & 2.12 & -0.41 to 4.665 \\
Non-survivors & 16 & 6.6250 & 3.8653 & & 6.0000 & \\
\hline
\end{tabular}

SOFA=Sequential organ failure assessment, $\mathrm{Cl}=$ Confidence interval

$\begin{aligned} & \text { Table 4: Number of patients according to SOFA } \\
& \text { score after } \mathbf{4 8} \mathbf{~}\end{aligned}$
\begin{tabular}{lcc}
$\mathbf{4 8} \mathbf{h}$ score & Survivors & Non-survivors \\
\hline$<7$ & 15 & 16 \\
$8-15$ & 1 & 8 \\
$>15$ & - & - \\
\hline SOFA=Sequential organ failure assessment
\end{tabular}

Out of 24 non-survivors, $\triangle$ SOFA score was higher in 15 patients $(62.5 \%)$ while it uniformly decreased in all survivors.

Incidence of septicemia and related mortality was more common in males $(65 \%)$ as compared to females (35\%). Sepsis was most commonly seen in the age group of $56-65$ years $(37.5 \%) .100 \%$ mortality was observed in those above 65 years.

Pneumonia (35\%) and urinary tract infection (32.5\%) were the most common etiologies for sepsis. Patients with pneumonia had the worst prognosis ( $85 \%$ mortality).

Organ dysfunction mainly involved coagulation in 40\%. Nervous system and liver involvement was seen in 32.5\% each and renal involvement in $30 \%$. Mortality was worst with dysfunction of nervous system (69\%), coagulation (68\%), and renal system (66\%) [Table 6].

Multi-organ dysfunction was seen in various combinations in 13 patients (32.5\%) out of whom, there were nine non-survivors [Table 7].

Diabetes mellitus (DM) (22.5\%) and alcoholic liver disease (17.5\%) were the most common co-morbidities. Causative agents could be identified in only $50 \%$ of patients. Gram-negative organisms were more prevalent, caused more severe illness and deaths as compared to gram positive organisms. Leucocytosis was seen in $90 \%$ at the time of presentation and $65 \%$ had persistent leucocytosis after $48 \mathrm{~h}$. The overall mortality was $76 \%$ in patients with persistent leucocytosis at the end of $48 \mathrm{~h}$.

\section{DISCUSSION}

Sepsis is the clinical manifestation of a systemic response of the body to infection or to an inflammatory-associated acute disease. ${ }^{[1,2]}$ There are many scoring systems to determine and predict prognosis of sepsis, such as Glasgow scale, SAPS II, APACHE, and SOFA. Studies have been performed to compare merits and prognostic ability of SAPS II with SOFA and APACHE with SOFA. ${ }^{[4,8]}$ In this study, The SOFA score was calculated to assess the severity of sepsis and multi-organ failure at presentation and after $48 \mathrm{~h}$. Furthermore, the causative organisms and clinical features of the sepsis syndromes were evaluated.
In this study, initially, SOFA score at admission to ICU was calculated. In the group of patients in whom SOFA was $<7$ at admission, there were $44 \%$ survivors. In patients who had SOFA score between 8 and 15 , there were $70 \%$ non-survivors. Mean SOFA score of the patients who did not survive, was 6.625 and the mean score of those who survived was 4.5 ( $t$-test $=1.69$, $P=0.0989)$. Minne et al. showed SOFA scores at admission had only slightly worse performance than APACHE II/III and were competitive with SAPS II models in predicting mortality in patients in the general medical and/or surgical ICU. Models with SOFA scores seem to have a comparable performance with other organ failure scores. ${ }^{[5]}$

Thereafter, the SOFA score at 48 h of admission was calculated. In the group of patients having SOFA score $<7$, there were $48 \%$ survivors and $52 \%$ non-survivors. In the patient group, which had scores of $8-15$, there were $88 \%$ non-survivors. Mean score of the patients who did not survive was 6.96 and the score in those who survived was 2.5 ( $t$-test $=4.33, P<0.001)$, which was statistically significant.

In a study by Ferreira et al., sequential assessment of organ dysfunction during the first few days of ICU admission was a good indicator of prognosis. Both mean and highest SOFA scores are particularly useful predictors of outcome. Independent of the initial score, an increase in SOFA score during the first $48 \mathrm{~h}$ in the ICU predicts a mortality rate of $50 \%{ }^{[5]}$ Thus, the results of this study collaborates with the results of the above mentioned studies.

In a study by Rangel-Frausto et al., mortality fell from $62 \%$ in the early 1990 s to $56 \%$ in 2000 . Mortality varies from $35 \%$ to $70 \%$, depending on factors such as age, co-morbidities, presence of acute lung injury, acute respiratory distress syndrome or renal failure, whether the infection is nosocomial or polymicrobial, and whether a fungus is the causative agent. ${ }^{[9-12]}$ In this study, out of 40 patients, the mortality was $62.5 \%(25)$, which meant that $37.5 \%$ (15) patients survived. Septic shock increases the length of stay in the ICU and hospital compared with patients without sepsis, ${ }^{[11,12]}$ and results in more organ dysfunction and greater use of the unit's resources. Septic shock also increases the risk of super-infections and neuromuscular complications associated with intensive care. ${ }^{[13]}$ In this study, sepsis was most commonly seen in the age group of $56-65$ years $(37.5 \%) ; 100 \%$ mortality was observed in those above 65 years. DM $(22.5 \%)$ and alcoholic liver disease (17.5\%) were the common co-morbidities. In a study by Annette et al., out of the overall population of patients with sepsis, those with DM were more likely to develop acute renal failure compared to those with no diabetes $(13 \%$ vs. $7 \%, P<0.05)$, and are less likely to develop acute respiratory failure ( $9 \%$ vs. $14 \%, P<0.05)$. 


\begin{tabular}{|c|c|c|c|c|c|c|}
\hline Outcome & Observation & Mean & Standard deviation & Mean difference & Median & $95 \% \mathrm{Cl}$ \\
\hline Survivors & 24 & 2.5625 & 2.5025 & 4.39 & 2.0000 & $2.34-6.44$ \\
\hline Non-survivors & 16 & 6.9583 & 3.4951 & & 6.5000 & \\
\hline
\end{tabular}

SOFA=Sequential organ failure assessment, $\mathrm{Cl}=$ Confidence interval

\begin{tabular}{lcc}
\multicolumn{3}{l}{ Table 6: Organ dysfunction and outcome } \\
\hline Organ dysfunction & Survivors & Non-survivors \\
\hline Cardiovascular & 3 & 6 \\
Lungs & 5 & 1 \\
Liver & 6 & 7 \\
Kidney & 4 & 8 \\
Central nervous system & 4 & 9 \\
Coagulation & 5 & 11 \\
\hline
\end{tabular}

\begin{tabular}{lcc}
\multicolumn{2}{c}{ Table 7: Multi-organ dysfunction and outcome } \\
\hline Organs involved & Survivors & Non-survivors \\
\hline$P+R+H$ & 0 & 2 \\
$P+R+N+H$ & 1 & 1 \\
$P+C+R S+N$ & 0 & 2 \\
$P+N$ & 0 & 2 \\
$P+C+R S+H$ & 1 & 0 \\
$P+C+H$ & 1 & 0 \\
$P+C$ & 0 & 1 \\
$P+R$ & 1 & 0 \\
$P+R+C$ & 0 & 1 \\
\hline$P=C o a$
\end{tabular}

$\mathrm{P}=$ Coagulation, $\mathrm{C}=$ Cardiac, $\mathrm{N}=$ Nervous system, $\mathrm{R}=$ Renal, $\mathrm{H}=$ Hepatic, RS=Respiratory system

In a study by Martin et al., incidence of sepsis was disproportionately increased in elderly adults, and age was an independent predictor of mortality. Compared with younger sepsis patients, elderly non-survivors of sepsis die earlier during hospitalization. ${ }^{[14]}$ Moreno et al. recently demonstrated that the initial SOFA score can be used to quantify the degree of organ dysfunction or failure present on admission and that the total maximum SOFA score can represent the cumulative organ dysfunction experienced by the patient. They also demonstrated a strong correlation of all these parameters with mortality outcome. ${ }^{[15]}$

Head-to-head comparison studies between SOFA and APACHE II showed that SOFA fared better as a predictor of outcome than APACHE II. ${ }^{[8]}$

\section{Limitations}

In this study, SOFA score was calculated at the time of presentation and after $48 \mathrm{~h}$. Serial, SOFA max and $\triangle$ SOFA scores were not measured. The sample size was rather small, so these results may not be applicable to ICUs on a large scale.

\section{CONCLUSIONS}

In this study, SOFA score at $48 \mathrm{~h}$ of admission was a better predictor of mortality $(P<0.001)$ than the score at admission. Both the mean and highest SOFA scores were particularly useful predictors of outcome. Hence, sequential assessment of organ dysfunction in patients of sepsis admitted to ICU is a good indicator of prognosis.

\section{REFERENCES}

1. Beal AL, Cerra FB. Multiple organ failure syndrome in the 1990s. Systemic inflammatory response and organ dysfunction. JAMA 1994;271:226-33.

2. Vincent JL, Bihari D. Sepsis, severe sepsis or sepsis syndrome: Need for clarification. Intensive Care Med 1992;18:255-7.

3. Russell JA, Singer J, Bernard GR, Wheeler A, Fulkerson W, Hudson L, et al. Changing pattern of organ dysfunction in early human sepsis is related to mortality. Crit Care Med 2000;28:3405-11.

4. Minne L, Abu-Hanna A, de Jonge E. Evaluation of SOFA-based models for predicting mortality in the ICU: A systematic review. Crit Care 2008;12:R161.

5. Ferreira FL, Bota DP, Bross A, Mélot C, Vincent JL. Serial evaluation of the SOFA score to predict outcome in critically ill patients. JAMA 2001;286:1754-8.

6. Bone RC, Balk RA, Cerra FB, Dellinger RP, Fein AM, Knaus WA, et al. Definitions for sepsis and organ failure and guidelines for the use of innovative therapies in sepsis. The ACCP/SCCM Consensus Conference Committee. American College of Chest Physicians/Society of Critical Care Medicine. Chest 1992;101:1644-55.

7. Brun-Buisson C, Doyon F, Carlet J. Bacteremia and severe sepsis in adults: A multicenter prospective survey in ICUs and wards of 24 hospitals. French Bacteremia-Sepsis Study Group. Am J Respir Crit Care Med 1996;154:617-24.

8. Halim D, Murni T, Redjeki I. Comparison of Apache II, SOFA, and modified SOFA Scores in predicting mortality of surgical patients in intensive care unit. Crit Care Shock 2009;12:157-69.

9. Martin GS, Mannino DM, Eaton S, Moss M. The epidemiology of sepsis in the United States from 1979 through 2000. N Engl J Med 2003;348:1546-54.

10. Rangel-Frausto MS, Pittet D, Hwang T, Woolson RF, Wenzel RP. The dynamics of disease progression in sepsis: Markov modeling describing the natural history and the likely impact of effective antisepsis agents. Clin Infect Dis 1998;27:185-90.

11. Annane D, Aegerter P, Jars-Guincestre MC, Guidet B, CUB-Réa Network. Current epidemiology of septic shock: The CUB-Réa Network. Am J Respir Crit Care Med 2003;168:165-72.

12. Alberti C, Brun-Buisson C, Burchardi H, Martin C, Goodman S, Artigas A, et al. Epidemiology of sepsis and infection in ICU patients from an international multicentre cohort study. Intensive Care Med 2002;28:108-21.

13. De Jonghe B, Sharshar T, Lefaucheur JP, Authier FJ, Durand-Zaleski I, Boussarsar $\mathrm{M}$, et al. Paresis acquired in the intensive care unit: A prospective multicenter study. JAMA 2002;288:2859-67.

14. Martin GS, Mannino DM, Moss M. The effect of age on the development and outcome of adult sepsis. Crit Care Med 2006;34:15-21.

15. Moreno R, Vincent JL, Matos R, Mendonça A, Cantraine F, Thijs L, et al. The use of maximum SOFA score to quantify organ dysfunction/failure in intensive care. Results of a prospective, multicentre study. Working Group on Sepsis related Problems of the ESICM. Intensive Care Med 1999;25:686-96.

How to cite this article: Bale C, Kakrani AL, Dabadghao VS, Sharma ZD. Sequential organ failure assessment score as prognostic marker in critically ill patients in a tertiary care intensive care unit. Int J Med Public Health 2013;3:155-8.

Source of Support: Nil, Conflict of Interest: None declared. 